\title{
Minimal Clinically Important Improvement of Routine Assessment of Patient Index Data 3 in Rheumatoid Arthritis
}

\author{
Michael M. Ward, Isabel Castrejon, Martin J. Bergman, Maria I. Alba, Lori C. Guthrie, \\ and Theodore Pincus
}

\begin{abstract}
Objective. To estimate minimal clinically important improvement (MCII) of RAPID-3 (Routine Assessment of Patient Index Data 3) in rheumatoid arthritis (RA).

Methods. RAPID-3 was computed before and after treatment escalation in a prospective study of adults with active RA. Patient judgment of improvement was used as the standard for a receiver-operating characteristic curve, from which MCII was estimated.

Results. Mean RAPID-3 improved from 16.3 to 11.1 between visits. MCII was -3.8 based on simultaneously optimized sensitivity and specificity, -3.5 using the 0.80 specificity criterion, and -4.1 using the Youden index.

Conclusion. RAPID-3 improvement of 3.8/30 units appears clinically meaningful. (First Release
\end{abstract} October 15 2018; J Rheumatol 2019;46:27-30; doi:10.3899/jrheum.180153)

\section{Key Indexing Terms: RHEUMATOID ARTHRITIS}

PATIENT-REPORTED OUTCOMES

RAPID-3
Rheumatoid arthritis (RA) is assessed using pooled indices based on the 7 -item RA core set ${ }^{1}$. The 28 -joint count Disease Activity Score (DAS28) ${ }^{2}$ and the Simplified Disease Activity Index $(\mathrm{SDAI})^{3}$ are important indices used in almost all recent clinical trials and many observational studies. However, these indices often are not used by US rheumatologists to monitor patient status quantitatively in routine care, because they require a formal joint count and laboratory tests ${ }^{4}$.

RAPID-3 (Routine Assessment of Patient Index Data 3) is an index that includes only the 3 patient-reported measures from the RA core set - physical function, pain, and patient's global assessment (PtGA). RAPID-3 was developed initially for feasibility in routine care, because the patient provides the data while in the waiting area ${ }^{5}$. RAPID-3 is highly correlated with the DAS28 and the Clinical Disease Activity Index ${ }^{6}$, and it is similar to those indices in its capacity to

From the Intramural Research Program, US National Institute of Arthritis and Musculoskeletal and Skin Diseases (NIAMS), National Institutes of Health (NIH), Bethesda, Maryland; Division of Rheumatology, Rush University Medical Center, Chicago, Illinois; Rheumatology, Taylor Hospital, Ridley Park, Pennsylvania, USA.

This study was supported in part by the Intramural Research Program, NIAMS, NIH, and US Public Health Service grant AR45177.

M.M. Ward, MD, MPH, Intramural Research Program, NIAMS, NIH;

I. Castrejon, $M D, P h D$, Division of Rheumatology, Rush University Medical Center; M.J. Bergman, MD, Rheumatology, Taylor Hospital; M.I. Alba, MD, Intramural Research Program, NIAMS, NIH; L.C. Guthrie, BSN, Intramural Research Program, NIAMS, NIH; T. Pincus, MD

Division of Rheumatology, Rush University Medical Center.

Address correspondence to Dr. M.M. Ward, Intramural Research Program, NIAMS/NIH, Building 10 CRC, Room 4-1339, 10 Center Drive, Bethesda, Maryland 20892-1468,USA.E-mail:wardm1@mail.nih.gov

Accepted for publication July 19, 2018. distinguish active from control treatment in clinical trials ${ }^{6}$. RAPID-3 is more likely than an erythrocyte sedimentation rate (ESR) to demonstrate incomplete responses to methotrexate ${ }^{7}$. Further, patient self-report questionnaires have higher reproducibility than physician-performed joint counts $^{8}$.

Results of clinical trials using any index are interpreted primarily according to statistical significance of treatment differences. A further criterion involves the clinical importance of these changes, according to thresholds for minimal clinically important improvement (MCII), to recognize whether the change is clinically meaningful to patients ${ }^{9,10}$. Estimates of the MCII of RAPID-3 have not been reported, but are of interest to aid in the interpretation of changes in the RAPID-3 with treatment ${ }^{11}$. We used data from a previous longitudinal observational study to estimate the MCII of RAPID-3.

\section{MATERIALS AND METHODS}

Clinical study. Adults with active RA were enrolled in a prospective study with the goal of determining clinically important changes in RA activity measures ${ }^{9}$. Active RA was defined as the presence of 6 or more tender joints, and assessment by the treating rheumatologist that RA was active and escalation of antirheumatic treatment was indicated. The study measured changes in RA activity before and after treatment escalation. Patients were enrolled who were being prescribed either prednisone, a new disease-modifying medication, or a new biological, or had an increase in dose of a current medication at the baseline study visit. The choice of medication was left to the participant's rheumatologist. The study protocol was approved by the US National Institute of Diabetes and Digestive and Kidney Diseases/National Institute of Arthritis and Musculoskeletal and Skin Disease institutional review board (03-AR-0133). All participants provided written informed consent.

Personal non-commercial use only. The Journal of Rheumatology Copyright $\subset$ 2019. All rights reserved. 
Measurements. Participants were evaluated at 2 visits: baseline and either 1 month (prednisone-treated patients) or 4 months (all others) later. The timing of the second visit was earlier for the prednisone group because their responses were anticipated to occur sooner. The same assessments were performed at both visits. Physical function was measured using the Health Assessment Questionnaire Disability Index (HAQ-DI) ${ }^{12}$ as a $0-3$ score (higher scores indicate more limitations in physical function). Pain severity was rated on a 0-100 visual analog scale (VAS), with anchors of no pain and severe pain. PtGA was also recorded on a 0-100 VAS, with anchors of very well and very poor. The HAQ-DI, pain score, and PtGA were each rescaled to $0-10$ and summed to provide the RAPID-3 (possible range $0-30)^{11}$

At the second visit, participants also completed an independent transition question on whether they judged their arthritis overall to be improved, unchanged, or worsened since the baseline visit ${ }^{13,14}$. This judgment was used as the standard against which changes in the RAPID-3 were compared. Participants further rated the importance of any improvement on a 7-point scale ranging from "almost none, hardly important at all" to "extremely important." Further details concerning participants and measurements are found in the previous report ${ }^{9}$.

Statistical analysis. The capacity of RAPID-3 and its component measures to identify changes in RA activity was studied by examining associations of changes in these measures with levels of patient-reported improvement. Sensitivity to change is a prerequisite for determining the MCII to avoid labeling small changes of insensitive measures as meaningful. Sensitivity to change was assessed using standardized response means (SRM), computed as the mean change divided by the SD of the change. We considered an absolute SRM of 0.50 or greater $(-0.50$ or smaller for improvements) to indicate good sensitivity to change. We used 2000 bootstrapped samples to compute $\mathrm{CI}$ for the $\mathrm{SRM}^{9}$.

The MCII for RAPID-3 was determined using a receiver-operating characteristic (ROC) curve, with the participant's subjective judgment of improvement (improved vs stayed the same or worsened) as the standard. Three alternate criteria were used to determine the MCII: the change in RAPID-3 that corresponded to a specificity for improvement of 0.80 , the Youden index, and the minimal distance of the upper left corner of the ROC plot (which maximized sensitivity and specificity simultaneously). We computed CI for these estimates based on 2000 bootstrapped samples ${ }^{9}$. The area under the ROC curve (AUC) for RAPID-3 was used to assess the discrimination of this measure. SAS programs, version 9.3 (SAS Institute), were used for analyses.

\section{RESULTS}

The 250 participants who completed both study visits included 195 women (78\%), and had a mean (SD) age of 51.0 (13.7) years and a median duration of RA of 6.4 years. Twenty-four percent had RA for $<2$ years. Participants had active RA at baseline, with a mean RAPID-3 of 16.3 (6.3), mean DAS28-ESR of 6.16 (1.2), and mean SDAI of 38.6 (14.8).

RAPID-3 and each of its components improved substantially during the study (Table 1). The SRM indicated that the RAPID-3 had good sensitivity to change. There was a graded change in the RAPID-3 across categories of patient-reported improvement, indicating construct validity. Among the 167 patients who reported improvement in their overall arthritis status at the followup visit, $92 \%$ rated their improvement as at least moderately important (fourth of 7 levels of importance).

RAPID-3 demonstrated excellent discrimination, with an AUC of 0.80 (95\% CI 0.74-0.86; Figure 1). The MCII for the RAPID-3 was -3.8 for the estimate that simultaneously optimized sensitivity and specificity (Table 2). The MCII estimate was -3.5 using the 0.80 specificity criterion, and -4.1 using the Youden index criterion.

\section{DISCUSSION}

In our study, the MCII for RAPID-3 among patients with active RA was -3.8 , based on the conventionally used method that simultaneously optimized sensitivity and specificity. The MCII estimate was slightly higher if based on the Youden index, and slightly lower if based on a set sensitivity of 0.80. Discrimination of improvement by RAPID-3 was similar to that of the DAS28-ESR (0.77) and SDAI $(0.78)^{9}$. The MCII estimates were similar to the threshold of -3.6 proposed as part of the definition of a "good" RAPID-3 response ${ }^{15}$.

Patients in our study appeared typical of patients with active RA in other trials ${ }^{8}$. Most patients had substantial responses to treatment escalation, and the sensitivity to change of clinical measures was similar to previous reports ${ }^{16,17}$. Importantly, the variation needed to identify MCII was seen, because 33\%-39\% did not judge themselves as improved ${ }^{8}$. Improvements were rated as highly important by most patients who reported improvement. Because the MCII is dependent on the baseline level of activity, it is appropriate to apply these estimates only to groups of patients with similarly high levels of RA activity ${ }^{18}$. MCII for improvement are less relevant for patients with low RA activity, because they are closer to an acceptable symptom state. The margin for symptom improvement becomes

Table 1. Changes in RAPID-3 and its component measures during the study.

\begin{tabular}{|c|c|c|c|c|c|c|c|c|}
\hline \multirow[t]{2}{*}{$\begin{array}{l}\text { Measure (possible } \\
\text { range) }\end{array}$} & \multirow[t]{2}{*}{ Baseline* } & \multirow[t]{2}{*}{ Followup* } & \multirow[t]{2}{*}{ Mean Change* } & \multirow[t]{2}{*}{$\operatorname{SRM}(95 \% \mathrm{CI})$} & \multicolumn{3}{|c|}{$\begin{array}{c}\text { Mean Change by Subjective } \\
\text { Improvement in Overall Arthritis Status }\end{array}$} & \multirow{2}{*}{$\begin{array}{c}\mathrm{p} \\
(\mathrm{ANOVA})\end{array}$} \\
\hline & & & & & $\begin{array}{l}\text { Improved, } \\
\mathrm{n}=167\end{array}$ & $\begin{array}{l}\text { Stayed the } \\
\text { Same, } \mathrm{n}=59\end{array}$ & $\begin{array}{c}\text { Worsened, } \\
\mathrm{n}=24\end{array}$ & \\
\hline RAPID-3 (0-30) & $16.3 \pm 6.3$ & $11.1 \pm 6.7$ & $-5.2 \pm 6.5$ & $-0.79(-0.71$ to -0.88$)$ & -7.2 & -2.0 & 1.0 & $<0.0001$ \\
\hline $\operatorname{PtGA}(0-10)$ & $5.5 \pm 2.5$ & $3.7 \pm 2.4$ & $-1.8 \pm 2.6$ & $-0.68(-0.60$ to -0.77$)$ & -2.5 & -0.7 & 0.3 & $<0.0001$ \\
\hline Pain $(0-10)$ & $6.0 \pm 2.5$ & $4.0 \pm 2.7$ & $-2.1 \pm 3.0$ & $-0.69(-0.61$ to -0.78$)$ & -3.0 & -0.8 & 0.2 & $<0.0001$ \\
\hline
\end{tabular}

* Mean \pm SD. ${ }^{\dagger}$ Transformed from the original 0-3 scale. RAPID-3: Routine Assessment of Patient Index Data 3; SRM: standardized response mean; HAQ-DI: Health Assessment Questionnaire-Disability Index; PtGA: patient's global assessment. 


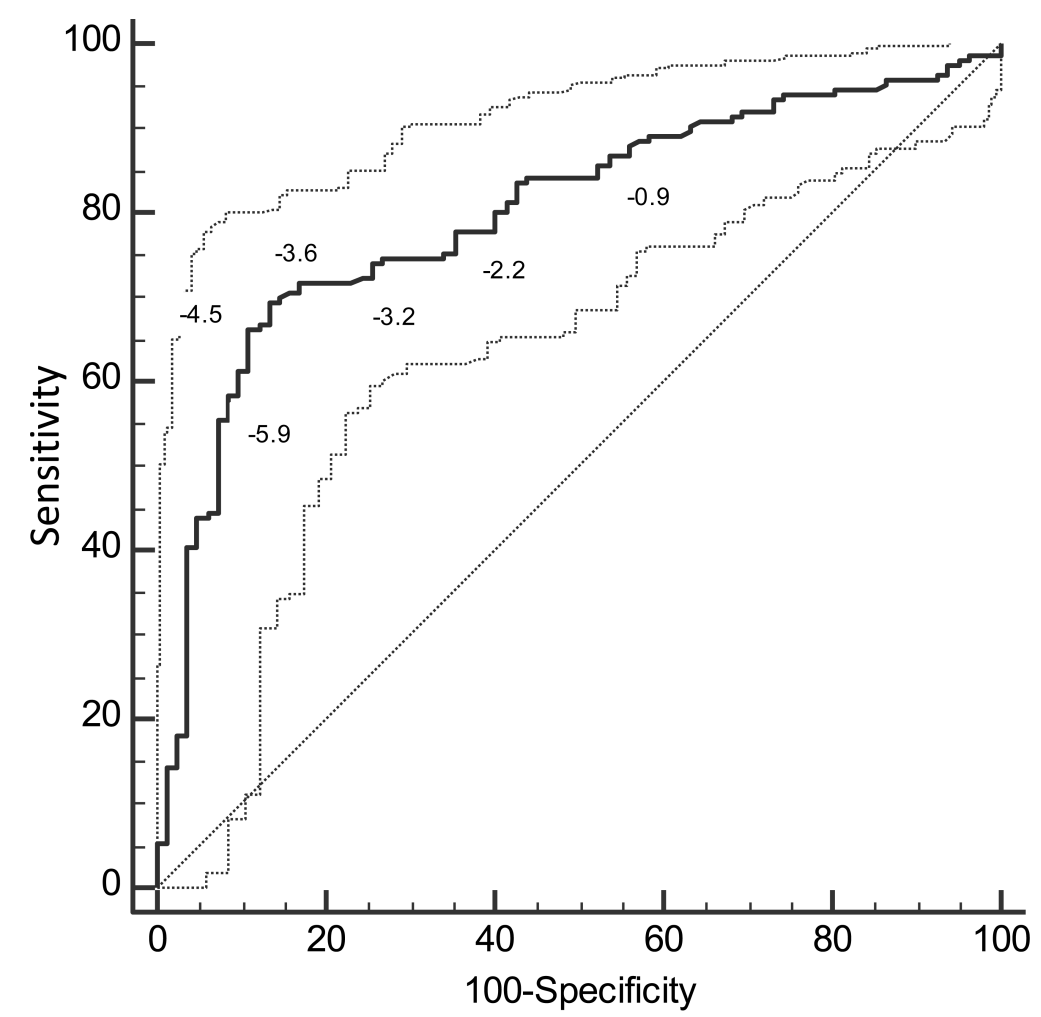

Figure 1. Receiver-operating characteristic curve for the RAPID-3. The dotted lines represent $95 \%$ confidence limits around the curve. The diagonal is the line of equivalence. RAPID-3: Routine Assessment of Patient Index Data 3.

Table 2. Minimal clinically important improvement (MCII) estimates for RAPID-3, using either the minimal distance to 0.1 on the receiver-operating characteristic curve (which maximizes specificity and sensitivity simultaneously), a set specificity of 0.80 , or the Youden index as the criterion, and the subjective change in global arthritis status as the standard. Values are based on the mean of 2000 bootstrapped samples.

\begin{tabular}{lccc}
\hline Criterion & MCII $(95 \%$ CI $)$ & Sensitivity (95\% CI) & Specificity (95\% CI) \\
\hline Minimal distance to 0.1 & $-3.8(-3.1$ to -4.4$)$ & $0.71(0.66-0.77)$ & $0.84(0.79-0.90)$ \\
Specificity 0.80 & $-3.5(-2.9$ to -4.3$)$ & $0.71(0.65-0.78)$ & $0.80(0.78-0.82)$ \\
Youden index & $-4.1(-3.6$ to -4.6$)$ & $0.69(0.63-0.76)$ & $0.87(0.81-0.94)$ \\
\hline
\end{tabular}

RAPID-3: Routine Assessment of Patient Index Data 3.

smaller and ultimately indiscernible as the level of activity decreases.

Several limitations are present in our current study. First, improvement was judged by the patient, and patient self-report measures tend to be more correlated with one another than with physical examination measures ${ }^{19}$. However, it may be argued that patient judgment is the only valid judgment for this purpose, because they are the persons experiencing the change. We also did not study differences with the timing of the second assessment, although previous studies suggest that MCII is not related to the assessment interval. Third, we did not study worsening or estimate the minimal clinically important difference. An equivalent increase of the RAPID-3 should not be taken as an estimate of important worsening, as MCII for improvement and worsening are asymmetric ${ }^{10}$. Fourth, all RA indices function effectively as indicators of inflammatory activity in clinical trials, but also may be influenced by joint damage and patient distress. Fifth, the results are applicable only to RA, although RAPID-3 has been found informative in many rheumatic disease ${ }^{20}$. Sixth, the cohort was moderate in size, and MCII should be tested in other cohorts.

Nonetheless, the findings provide new information on the interpretation of changes in RAPID-3 at the group level. Clinicians may feel comfortable documenting and monitoring patient status, recognizing an improvement of 3.8 units in patients with active RA to be meaningful in routine patient care.

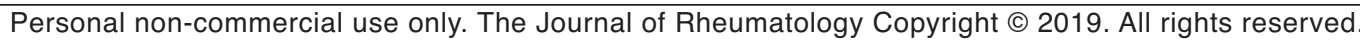




\section{REFERENCES}

1. Boers M, Tugwell P, Felson DT, van Riel PL, Kirwan JR, Edmonds JP, et al. World Health Organization and International League of Associations for Rheumatology core endpoints for symptom modifying antirheumatic drugs in rheumatoid arthritis clinical trials. J Rheumatol Suppl. 1994 Sep;41:86-9.

2. Prevoo ML, van 't Hof MA, Kuper HH, van Leeuwen MA, van de Putte LB, van Riel PL. Modified disease activity scores that include twenty-eight-joint counts. Development and validation in a prospective longitudinal study of patients with rheumatoid arthritis. Arthritis Rheum 1995;38:44-8.

3. Aletaha D, Smolen JS. The Simplified Disease Activity Index and Clinical Disease Activity Index to monitor patients in standard clinical care. Rheum Dis Clin North Am 2009;35:759-72.

4. Curtis JR, Chen L, Danila MI, Saag KG, Parham KL, Cush JJ. Routine use of quantitative disease activity measurements among US rheumatologists: implications for treat-to-target management strategies in rheumatoid arthritis. J Rheumatol 2018;45:40-4.

5. Pincus T, Yazici Y, Bergman M, Maclean R, Harrington T. A proposed continuous quality improvement approach to assessment and management of patients with rheumatoid arthritis without formal joint counts, based on quantitative routine assessment of patient index data (RAPID) scores on a multidimensional health assessment questionnaire (MDHAQ). Best Pract Res Clin Rheumatol 2007;21:789-804.

6. Pincus T, Castrejon I. Are patient self-report questionnaires as "scientific" as biomarkers in "treat-to-target" and prognosis in rheumatoid arthritis? Curr Pharm Des 2015;21:241-56.

7. Pincus T. RAPID 3 , an index of only 3 patient self-report core data set measures, but not ESR, recognizes incomplete responses to methotrexate in usual care of patients with rheumatoid arthritis. Bull Hosp Jt Dis 2013;71:117-20.

8. Uhlig T, Kvien TK, Pincus T. Test-retest reliability of disease activity core set measures and indices in rheumatoid arthritis. Ann Rheum Dis 2009;68:972-5.

9. Ward MM, Guthrie LC, Alba MI. Clinically important changes in individual and composite measures of rheumatoid arthritis activity: thresholds applicable in clinical trials. Ann Rheum Dis 2015;74:1691-6.

10. Wells GA, Tugwell P, Kraag GR, Baker PRA, Groh J, Redelmeier DA. Minimum important difference between patients with rheumatoid arthritis: the patients' perspective. J Rheumatol 1993;20:557-60.
11. Pincus T. Can RAPID3, an index without formal joint counts or laboratory tests, serve to guide rheumatologists in tight control of rheumatoid arthritis in usual clinical care? Bull NYU Hosp Jt Dis 2009;67:254-66.

12. Fries JF, Spitz P, Kraines RG, Holman HR. Measurement of patient outcome in arthritis. Arthritis Rheum 1980;23:137-45.

13. Jaeschke R, Singer J, Guyatt GH. Measurement of health status. Ascertaining the minimal clinically important difference. Control Clin Trials 1989;10:407-15.

14. Kvamme MK, Kristiansen IS, Lie E, Kvien TK. Identification of cutpoints for acceptable health status and important improvement in patient-reported outcomes, in rheumatoid arthritis, psoriatic arthritis, and ankylosing spondylitis. J Rheumatol 2010;37:26-31.

15. Pincus T, Hines P, Bergman MJ, Yazici Y, Rosenblatt LC, MacLean R. Proposed severity and response criteria for Routine Assessment of Patent Index Data (RAPID3): Results for categories of disease activity and response criteria in abatacept clinical trials. J Rheumatol 2011;38:2565-71.

16. Tugwell P, Wells G, Strand V, Maetzel A, Bombardier C, Crawford $\mathrm{B}$, et al. Clinical improvement as reflected in measures of function and health-related quality of life following treatment with leflunomide compared with methotrexate in patients with rheumatoid arthritis: sensitivity and relative efficiency to detect a treatment effect in a twelve-month, placebo-controlled trial. Leflunomide Rheumatoid Arthritis Investigators Group. Arthritis Rheum 2000;43:506-14.

17. Ranganath VK, Yoon J, Khanna D, Park GS, Furst DE, Elashoff DA, et al. Comparison of composite measures of disease activity in an early seropositive rheumatoid arthritis cohort. Ann Rheum Dis 2007;66:1633-40.

18. Ward MM, Guthrie LC, Alba M. Dependence of the minimal clinically important improvement on the baseline value is a consequence of floor and ceiling effects and not different expectations of patients. J Clin Epidemiol 2014;67:689-96.

19. Castrejon I, McCollum L, Tanriover MD, Pincus T. Importance of patient history and physical examination in rheumatoid arthritis compared to other chronic diseases: Results of a physician survey. Arthritis Care Res 2012;64:1250-5.

20. Castrejon I. The use of MDHAQ/RAPID3 in different rheumatic diseases: a review of the literature. Bull Hosp Jt Dis 2017;75:93-100. 